\title{
Masking effect of anti-androgens on androgenic activity in European river sediment unveiled by effect-directed analysis
}

\author{
Jana M. Weiss • Timo Hamers • Kevin V. Thomas • \\ Sander van der Linden • Pim E. G. Leonards • \\ Marja H. Lamoree
}

Received: 25 February 2009/Revised: 14 April 2009/Accepted: 16 April 2009/Published online: 6 May 2009

(C) The Author(s) 2009. This article is published with open access at Springerlink.com

\begin{abstract}
This study shows that the androgen receptor agonistic potency is clearly concealed by the effects of androgen receptor antagonists in a total sediment extract, demonstrating that toxicity screening of total extracts is not enough to evaluate the full in vitro endocrine disrupting potential of a complex chemical mixture, as encountered in the environment. The anti-androgenic compounds were masking the activity of androgenic compounds in the extract with relatively high anti-androgenic potency, equivalent to $200 \mathrm{nmol}$ flutamide equivalents/g dry weight. A two-step serial liquid chromatography fractionation of the extract successfully separated anti-androgenic compounds from androgenic compounds, resulting in a total androgenic potency of $3,820 \mathrm{pmol}$ dihydrotestosterone equivalents/g dry weight. The fractionation simplified the chemical identification analysis of the original complex sample matrix. Seventeen chemical structures were tentatively identified. Polyaromatic hydrocarbons, a technical mixture of nonylphenol and dibutyl phthalate were identified to contribute to the anti-androgenic potency observed in the
\end{abstract}

J. M. Weiss $\cdot$ T. Hamers · P. E. G. Leonards • M. H. Lamoree $(\bowtie)$

Institute for Environmental Studies (IVM),

Faculty of Earth and Life Sciences, VU University,

De Boelelaan 1087,

1081 HV Amsterdam, The Netherlands

e-mail: marja.lamoree@ivm.vu.nl

K. V. Thomas

Norwegian Institute for Water Research (NIVA),

Gaustadalléen 21,

0349 Oslo, Norway

S. van der Linden

BioDetection Systems (BDS) B.V.,

Science Park 406,

1098 XH Amsterdam, The Netherlands river sediment sample. With the GC/MS screening method applied here, no compounds with AR agonistic disrupting potencies could be identified. Seventy-one unidentified peaks, which represent potentially new endocrine disrupters, have been added to a database for future investigation.

Keywords Androgenicity · Androgen receptor (AR) - Effectdirected analysis (EDA) · Sediment · Polycyclic aromatic hydrocarbons (PAHs) $\cdot$ MODELKEY

\section{Introduction}

In areas influenced by anthropogenic activity, the environment is often contaminated by a complex mixture of substances that may have toxicological effects on organisms. One arising concern has been the world-wide observation of effects consistent with exposure to endocrine disrupting compounds in invertebrates, fish, wildlife and even humans [1-3]. Endocrine disrupting effects can be profound due to the role hormones play in the development of an organism. Androgens are one group of these crucial hormones. Androgens stimulate and control the development and maintenance of masculine characteristics by binding to the androgen receptor (AR) and inducing a cascade of hormone responses. This includes the activity of the accessory male sex organs and development of male secondary sex characteristics. Androgens are also the precursor of all estrogens, the female sex hormones. Androgen-mediated dysfunction has been reported in fish, such as skewed sex ratio, masculinisation of females, disturbed relative weight and histopathology [2]. Sexual dimorphism in fish has been demonstrated to be affected by both androgens and estrogens [4]. Also, vitellogenin 
induction, normally a measure of estrogenic activity, has been observed in both sexes probably as a result of aromatisation of androgens. Synthetic androgens (anabolic steroids) are used to promote muscle strength in humans (e.g. athletes) and animals [5, 6], to increase the meat quantity in farm animals [7], and in androgen replacement therapies [8]. Synthetic and natural androgenic steroids (such as methyl-testosterone and testosterone, respectively) bind to the androgen receptor (AR), inducing an activation of the receptor (AR agonism) leading to transcription of genes responsible for androgenic effects. It has been found that environmental pollutants, e.g. pesticides and industrial chemicals, can interfere with the androgen system in both wildlife and humans, mainly as anti-androgens [2]. Antiandrogens (such as the anti-androgenic drug flutamide) can bind to the AR, but are unable to activate the receptor (AR antagonism).

To fully investigate the androgenic potential of the sediment extract, we followed an effect-directed analysis approach (EDA). EDA has been developed in order to identify toxic compounds in the environment [9]. EDA studies use bioassay-directed fractionation techniques in order to select those fractions containing toxic compounds, and hence perform a toxicity characterization of the sample. In EDA, a non-destructive clean up procedure is used which enables the inclusion of as many compounds as possible present in a sample that exert a specific mode of action in a bioassay, i.e. a non-selective identification of relevant compounds that may cause a specific effect in the environment [9]. The aim is, with the assistance of bioassays responding to specific toxicological/biological endpoint(s), to select active fractions of the sample for further fractionation in order to simplify the complexity of the extracts. The final goal is to identify-by chemical analytical means - the effect-causing compounds in the active fractions.

The EDA approach has successfully been applied to evaluate endocrine potencies in several water systems, such as wastewater treatment plants $[10,11]$, rivers [11-13], harbour areas [14, 15] marine sediments [16] and biota [17]. For example, almost $100 \%$ of estrogenic and androgenic activity in fish bile and effluents from wastewater treatment plants can be explained by the occurrence of natural and synthetic steroids [11, 17]. An earlier published review further describes a range of important results obtained from bioassay-directed studies [9].

The study presented here focuses on a sediment sample from the river Scheldt water basin collected close to Antwerp (Belgium). This sample was selected after a toxicity characterization of three European river systems (11 samples from the rivers: Elbe in the Czech Republic and Germany; Llobregat in Spain; Scheldt in Belgium and The Netherlands) within the EU funded MODELKEY project (SSPI-CT-2003-511237-2; http://www.modelkey. ufz.de/). The bioassay used to direct the analysis is the Chemically Activated Luciferase gene eXpression assay for androgen detection (AR CALUX ${ }^{\circledR}$ ), for both agonistic and antagonistic responses, expressed as dihydrotestosterone (DHT) equivalents and flutamide (FLU) equivalents, respectively. The sediment extract chosen for further EDA investigation in this study was selected because it had the highest anti-androgenic (i.e. AR antagonistic) potency after initial toxicity screening. No androgenic (i.e. AR agonistic) potency was observed.

The aim of the work described here was to use an EDA approach to evaluate the full androgenic potential in a sediment sample from a European river system. Because the presence of AR agonists may be masked by the presence of AR antagonists in the sample, this includes AR agonistic screening of the fractions of the original AR antagonistic Scheldt sample. Potent compounds in the bioassay are tentatively identified by qualitative Gas Chromatography-Mass Spectrometry (GC/MS) screening.

\section{Materials and methods}

\section{Sample information}

The sediment sample that has been investigated is from the river Schijn, a tributary to the river Scheldt, at the location Eenhoorn, Wijnegem $\left(51^{\circ} 13^{\prime} 13.77^{\prime \prime} \mathrm{N}, 4^{\circ} 32^{\prime} 50.79^{\prime \prime} \mathrm{E}\right)$, close to Antwerp in Belgium (Fig. 1). Eenhoorn is situated below the outlet of the Grote Merriebeek, which is a water-stream canalised through an industrialised area, parallel to the Albert Canal, and is a point discharge of polluted water into the Schijn.

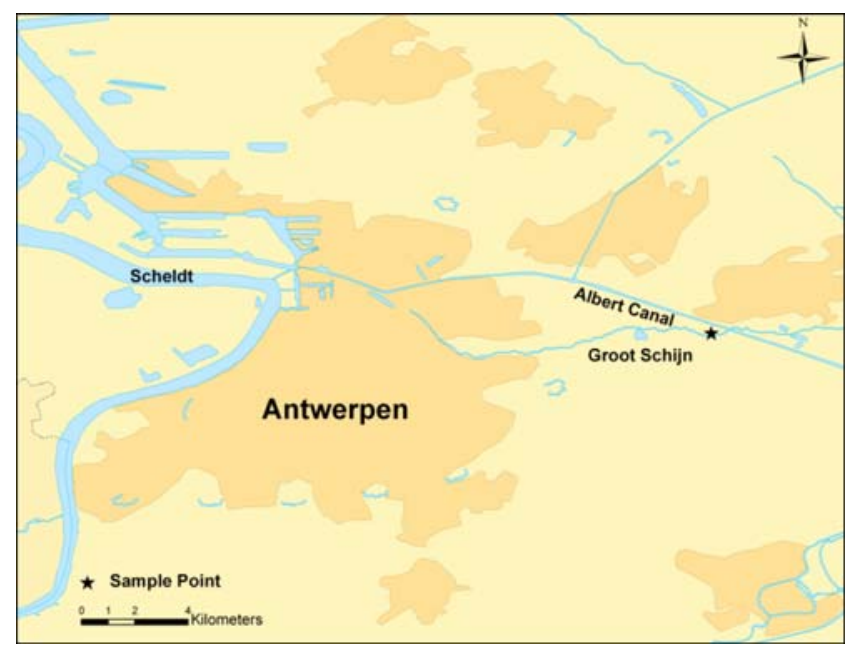

Fig. 1 Map of sediment sampling area in Belgium, close to Antwerp, location Eenhoorn (star) 
Sediment (top 10-20-cm layer) was sampled in June 2006 with a hand-operated Ponar grab. The sediment contained fine muddy particles, was rich in organic material and was darkly coloured with light oily specks that were observed during sampling. The dry weight of the sample as received was $24 \%$. The sample was stored in a climate room $\left(4{ }^{\circ} \mathrm{C}\right)$ until analysis. Before clean up, it was sieved $(125 \mu \mathrm{m})$ followed by freeze drying.

Pre-treatment procedure

All solvents were pro analysis quality or better and were purchased from JT baker (The Netherlands) or Merck (Germany) unless stated otherwise. The pre-treatment procedure is outlined in Fig. 2.

\section{Extraction}

The extraction method used for the sediment sample ( $40 \mathrm{~g}$ dry weight $[\mathrm{dw}]$ ) was Accelerated Solvent Extraction (ASE), an exhaustive extraction method [18]. Dichloromethane (DCM): acetone $(3: 1, v / v)$ was used as extraction solvent. ASE extractions were performed at $50^{\circ} \mathrm{C}$, $2,000 \mathrm{psi}$, with three extraction cycles [15]. Extracts were evaporated under a gentle $\mathrm{N}_{2}$-gas stream until almost dryness and re-dissolved in DCM $(1 \mathrm{ml})$.

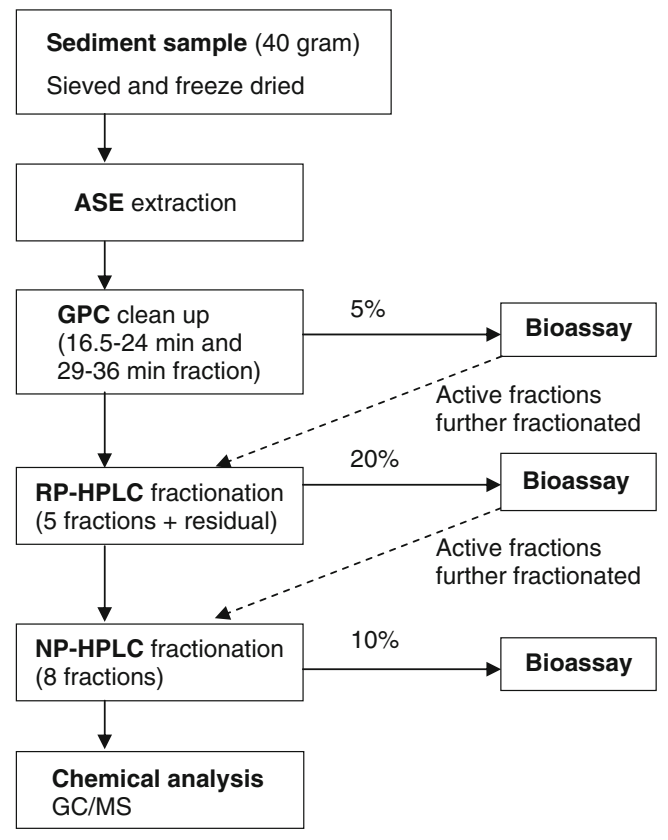

Fig. 2 An outline of the pre-treatment procedure used in the effectdirected analysis of the sediment sample

\section{Gel permeation chromatography for clean up}

The ASE-extract was cleaned up using Gel Permeation Chromatography (GPC) equipped with two polystyrenedivinylbenzene columns in series $(10 \mu \mathrm{m}, 50 \AA, 600 \times$ $25 \mathrm{~mm}$, Polymer Laboratories) and with $10 \mathrm{ml} / \mathrm{min}$ DCM as eluent [19]. The ASE-extract was injected via a $1.5-\mathrm{ml}$ injection loop onto the GPC column. The major part of the matrix elutes in the first fraction up to ca 18 min following injection. Based on the results of the elution profile of test compounds [19], the fraction 16:30-24:00 min was collected (fraction GPC1). The fraction containing sulphur, which is known to be cytotoxic in the bioassay, elutes between 25 and $29 \mathrm{~min}$ and was discarded. Another fraction was also collected (29-36 min) after the heart cut of sulphur to see if late-eluting androgenic or antiandrogenic compounds were present (fraction GPC2). The separate GPC-extracts were split, 5\% was used for direct bioassay analysis (evaporated to dryness and re-dissolved in $100 \mu \mathrm{l}$ dimethylsulfoxide [DMSO, spectrophotometric grade, 99.9\%, Acros, Belgium]), and the remaining 95\% was used for high-performance liquid chromatography (HPLC) fractionation (evaporated to dryness and redissolved in methanol $[\mathrm{MeOH}]$ : water $\left.\left[\mathrm{H}_{2} \mathrm{O}\right], 1: 1 v / v\right)$.

Only the first GPC fraction (GPC1, $20 \mathrm{~g}$ sediment $/ \mathrm{ml}$ ) showed activity in the bioassay and was further analysed. Due to the lack of bioassay response (both AR agonistic as well as AR antagonistic) in GPC fraction 2, this fraction was not included in the rest of the study.

\section{Reversed phase fractionation}

The first fractionation was performed using a reversedphase (RP) HPLC system at $22{ }^{\circ} \mathrm{C}$, with a $\mathrm{C}_{18}$ semipreparative column (Vydac 201TP510, $5 \mu \mathrm{m}, 10.0 \times$ $250 \mathrm{~mm}$; mobile phase initially $50 \% \mathrm{MeOH}$ and $50 \%$ $\mathrm{H}_{2} \mathrm{O}$ (4.7 $\mathrm{ml} / \mathrm{min}$ ), changing linearly to $100 \% \mathrm{MeOH}$ in $50 \mathrm{~min}$ and kept at $100 \% \mathrm{MeOH}$ during $40 \mathrm{~min}$ ) [17]. The GPC-extract (GPC1) in $1 \mathrm{ml} \mathrm{MeOH}: \mathrm{H}_{2} \mathrm{O}(1: 1 v / v)$ was quantitatively injected and five fractions with time windows $0-9,9-24,24-42,42-63$ and $63-90 \mathrm{~min}$, indicated as fractions RP1-RP5, were collected. After quantitative injection, the vial was rinsed with hexane to dissolve any compounds possibly remaining on the vial wall that were too non-polar to dissolve in the carrier solvent $(\mathrm{MeOH}$ : $\mathrm{H}_{2} \mathrm{O}$ ) prior to fractionation. This non-polar residual fraction was evaporated and dissolved in $100 \mu \mathrm{LMSO}$ and tested with AR CALUX assays without further fractionation.

RP-HPLC fractions were evaporated with $\mathrm{N}_{2}$-gas at $40{ }^{\circ} \mathrm{C}$ and split into two portions: $20 \%$ was evaporated and dissolved in $100 \mu \mathrm{l}$ of DMSO ( $80 \mathrm{~g}$ sediment $/ \mathrm{ml}$ ) for AR CALUX measurements, while the remaining $80 \%$ of the active fractions in the bioassays were further fractionated. 


\section{Normal phase fractionation}

As the second step in the two-step serial fractionation strategy, the reversed-phase fractions were further fractionated into eight sub-fractions by Normal Phase (NP) HPLC with a Waters $\mu$ Porasil semi-preparative column (7.8× $300 \mathrm{~mm}$, particle size $10 \mu \mathrm{m}$; mobile phase initially $100 \%$ hexane $(5 \mathrm{~min}), 1 \% / \mathrm{min}$ of DCM for $5 \mathrm{~min}, 4 \% / \mathrm{min}$ of DCM for $25 \mathrm{~min}$ to $100 \%$ DCM $(10 \mathrm{~min})$ followed by $10 \% / \mathrm{min}$ of acetonitrile (ACN) for $5 \mathrm{~min}$, and then back to $100 \%$ DCM (5 min) and finally $6 \% / \mathrm{min}$ to $100 \%$ of hexane to re-equilibrate $(10 \mathrm{~min})$ as described by Fernandez and Bayona [20]. Around 14\% of the eluate of each NP fraction (NP1-NP8) was evaporated, dissolved in $50 \mu \mathrm{l}$ DMSO $(80 \mathrm{~g}$ sediment $/ \mathrm{ml})$ for AR CALUX measurements. The remaining extracts (re-dissolved in hexane) were used for chemical screening.

\section{Bioassays}

Androgenic and anti-androgenic potencies of the extract and its fractions were determined in the AR CALUX ${ }^{\circledR}$ bioassay (BioDetection Systems, Amsterdam, The Netherlands). The AR CALUX bioassay is a reporter gene assay, which consists of a human osteoblast cell line carrying a luciferase gene under transcriptional control of an androgen responsive element [21]. Dihydrotestosterone (DHT, Sigma-Aldrich, The Netherlands) and flutamide (FLU, Sigma-Aldrich, The Netherlands) are used as androgenic and anti-androgenic reference compounds, respectively.
The assay is performed according to the original publication by Sonneveld et al. [21] and AR agonistic and AR antagonistic responses are expressed as relative amounts of reference compound equivalents per $g$ of dry weight (dw) sediment. Triplicates of a dilution series in DMSO of the sediment total extracts and fractions were analysed. Doseresponse curves of the reference compounds were fitted using the sigmoidal fit with variable slope in GraphPad Prism (version 4.01 for Windows, GraphPad Software; Fig. 3a and $\mathrm{b}$ ). The amount of reference compound equivalents (eq) in the sample was determined by interpolating the response of the sample into the dose-response curve of the reference compound (Figs. $3 \mathrm{c}$ and d). A minimum of $1 \%$ induction was set as limit of detection (LOD) for androgenic effects, and 20\% inhibition for antagonistic androgenicity. The most diluted extract still containing activity higher than the LOD was used for quantification to avoid possible matrix effects. In order to avoid false positives, the results from the non-diluted fraction (x1) are not quantified (reported as + in Table 1) if activity was not observed in the next diluted fraction (x3).

As a confirmation step of the bioassay effect and the analytical quality (recovery) following normal phase subfractionation the sub-fractions were pooled into their original reversed-phase fractions constitution, i.e. RPXNP1 to RPXNP8 (where $X=2,3$ or 4 ) is pooled and evaporated into the same end volume as the original RPX fraction and re-analysed in the bioassay [22]. This will clarify whether the observed change in activity of the fractions are due to loss of potent androgenic compounds during fractionation,
Fig. 3 Reference compounds antagonistic flutamide (FLU) curve (a) and agonistic dihydrotestosterone (DHT) curve (b) in AR CALUX, which are expressed as $\%$ of inhibition at a constant DHT concentration (200 pM) and \% of induction compared to maximum DHT concentration $(10 \mathrm{nM})$, respectively. Illustrated in $\mathbf{c}$ is the sediment extract RP3NP2 AR antagonistic potency and $\mathbf{d}$ the sediment extract RP3NP7 AR agonistic potency, in a dilution series of $\times 1-\times 1,000$
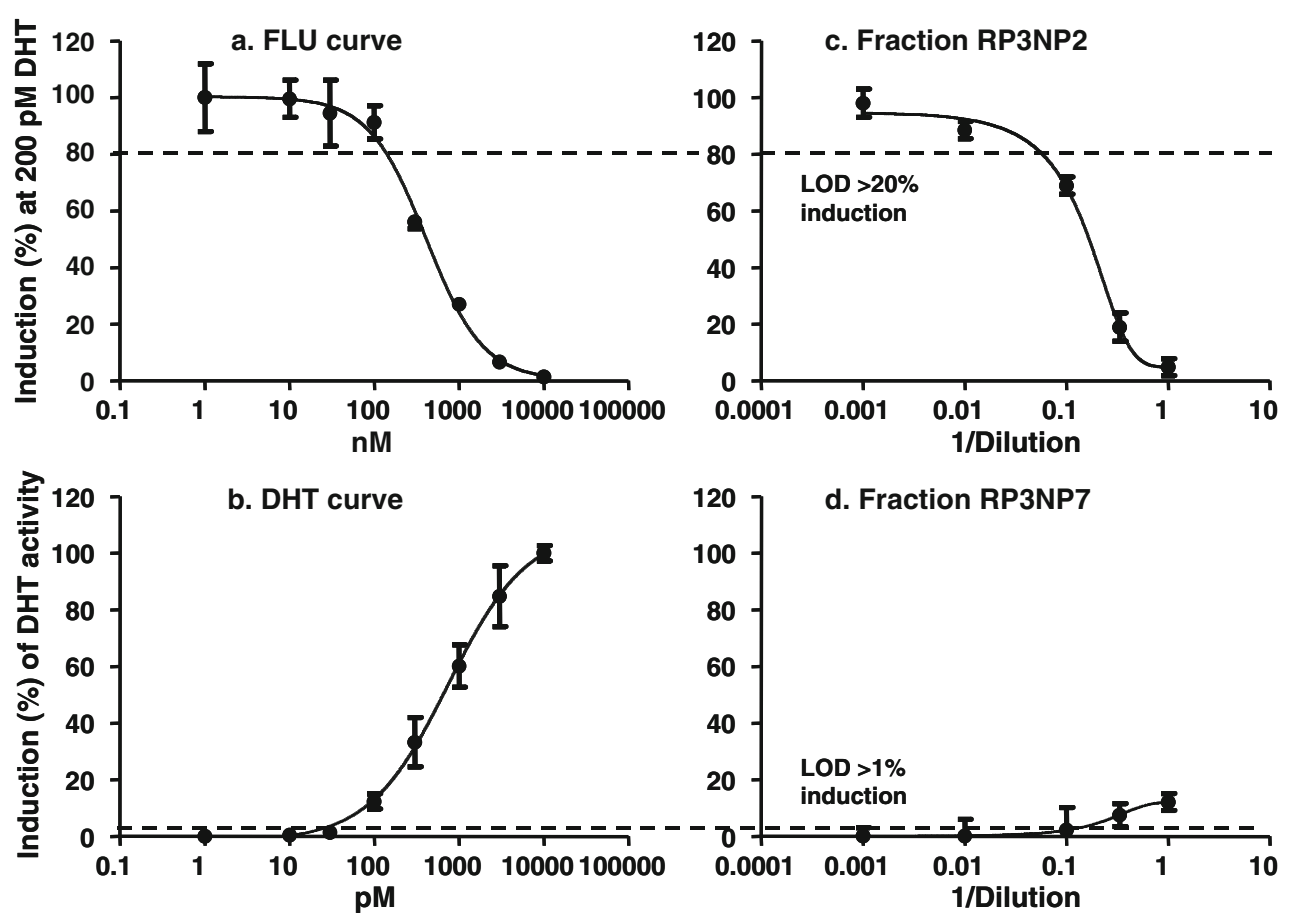
Table 1 The agonistic (ng and pmol of dihydrotestosterone (DHT) equivalents/g dw) and antagonistic ( $\mu \mathrm{g}$ and nmol flutamide (FLU) equivalents/g dw) androgenicity measured in GPC fraction 1 and 2, reversed-phase (RP) fractions, the residual (nondissoluble fraction at reversedphase fraction), normal phase (NP) fractions and pooled NP fractions

\begin{tabular}{|c|c|c|c|c|}
\hline & \multicolumn{2}{|c|}{ DHT equivalents } & \multicolumn{2}{|c|}{ FLU equivalents } \\
\hline & ng/g sed & $\mathrm{pmol} / \mathrm{g}$ sed & $\mu \mathrm{g} / \mathrm{g}$ sed & $\mathrm{nmol} / \mathrm{g}$ sed \\
\hline GPC fraction 1 (16.5-24 $\mathrm{min})$ & $<<$ & $<<$ & 55 & 200 \\
\hline GPC fraction 2 (29-36 $\mathrm{min})$ & $<<$ & $<<$ & $<<$ & $<<$ \\
\hline $\mathrm{RP} 1$ & $<<$ & $<<$ & $<<$ & $<<$ \\
\hline $\mathrm{RP} 2$ & 250 & 890 & + & + \\
\hline RP3 & 120 & 440 & 30 & 110 \\
\hline RP4 & $<<$ & $<<$ & 6.9 & 25 \\
\hline RP5 & $<<$ & $<<$ & $<<$ & $<<$ \\
\hline Residual fraction & $<<$ & $<<$ & $<<$ & $<<$ \\
\hline Sum RP & 370 & 1330 & 37 & 130 \\
\hline RP2NP1 & $<<$ & $<<$ & $<<$ & $<<$ \\
\hline RP2NP2 & $<<$ & $<<$ & $<<$ & $<<$ \\
\hline RP2NP3 & $<<$ & $<<$ & $<<$ & $<<$ \\
\hline RP2NP4 & $<<$ & $<<$ & $<<$ & $<<$ \\
\hline RP2NP5 & $<<$ & $<<$ & $<<$ & $<<$ \\
\hline RP2NP6 & $<<$ & $<<$ & + & + \\
\hline RP2NP7 & 120 & 420 & $<<$ & $<<$ \\
\hline RP2NP8 & $<<$ & $<<$ & $<<$ & $<<$ \\
\hline Pooled RP2NP1-8 & 320 & 1170 & + & + \\
\hline RP3NP1 & $<<$ & $<<$ & $<<$ & $<<$ \\
\hline RP3NP2 & $<<$ & $<<$ & 6.0 & 22 \\
\hline RP3NP3 & $<<$ & $<<$ & + & + \\
\hline RP3NP4 & $<<$ & $<<$ & + & + \\
\hline RP3NP5 & $<<$ & $<<$ & 2.4 & 8.8 \\
\hline RP3NP6 & $<<$ & $<<$ & 4.5 & 16 \\
\hline RP3NP7 & 940 & 3400 & $<<$ & $<<$ \\
\hline RP3NP8 & $<<$ & $<<$ & $<<$ & $<<$ \\
\hline Pooled RP3NP1-8 & 110 & 380 & 27 & 98 \\
\hline RP4NP1 & $<<$ & $<<$ & $<<$ & $<<$ \\
\hline RP4NP2 & $<<$ & $<<$ & 3.4 & 12 \\
\hline RP4NP3 & $<<$ & $<<$ & $<<$ & $<<$ \\
\hline RP4NP4 & $<<$ & $<<$ & $<<$ & $<<$ \\
\hline RP4NP5 & $<<$ & $<<$ & $<<$ & $<<$ \\
\hline RP4NP6 & $<<$ & $<<$ & $<<$ & $<<$ \\
\hline RP4NP7 & $<<$ & $<<$ & + & + \\
\hline RP4NP8 & $<<$ & $<<$ & $<<$ & $<<$ \\
\hline Pooled RP4NP1-8 & + & + & 9.3 & 34 \\
\hline Sum individual NP & 1060 & 3820 & 16 & 59 \\
\hline Sum pooled NP & 430 & 1550 & 36 & 130 \\
\hline
\end{tabular}

between analyses. The variance is high between experiments but considered acceptable since the responses are expressed as relative effect potencies and a dose-response curve of the reference compound is included in every experiment.

To evaluate the inter-laboratory stability of the bioassay, eight samples (GPC1, GPC2, RP1-RP5 and residual reversed-phase fraction) were analysed for AR antagonistic potency at two laboratories (IVM and BioDetection
The reproducibility of the $\mathrm{EC}_{50} \mathrm{~S}$ and $\mathrm{IC}_{50} \mathrm{~s}$ of the reference curves $(n=19)$ are expressed as coefficients of variation (CV) and were $47 \%$ for DHT and $19 \%$ for the FLU 
Systems). The results did not differ (paired $t$ test $p>0.05$ ) and the $\mathrm{CV}$ was determined to be $10 \%$ between laboratories (data not shown). To evaluate the inter-assay comparability, the reversed-phase fractions (RP1-RP5) were analysed in the yeast-based bioassay (YAS) for antagonistic androgenicity at the Centre for Environment, Fisheries and Aquaculture Science (CEFAS, Essex, United Kingdom). RP3 was successfully identified as the most potent AR antagonistic fraction but the reported value was 300 times higher $(9000 \mu \mathrm{g} / \mathrm{g} \mathrm{dw})$ than in the AR CALUX. This indicates the differences in response factors and the difficulties to compare results between assays, but also illustrates the comparability of the patterns of the observed toxicity.

\section{Chemical analysis}

All normal phase sub-fractions were screened with Gas Chromatography (GC, Agilent 6890) with a quadrupole Mass Selective Detector (MS, Agilent 5973), equipped with an SGE-BPX5 column $(25 \mathrm{~m}, 0.22 \mathrm{~mm}$ i.d., $0.3 \mu \mathrm{m}$ film thickness). Two microlitres of fractions (in hexane) were splitless injected. The column oven temperature programme was as follows: $60^{\circ} \mathrm{C}(1 \mathrm{~min}), 7^{\circ} \mathrm{C} / \mathrm{min}$ to $200^{\circ} \mathrm{C}(15 \mathrm{~min})$, $5^{\circ} \mathrm{C}$ to $265^{\circ} \mathrm{C}(5 \mathrm{~min})$ and finally $10^{\circ} \mathrm{C} / \mathrm{min}$ to $275^{\circ} \mathrm{C}$ (5 min). Run time, $60.00 \mathrm{~min}$. Helium was used as carrier gas $(1 \mathrm{ml} / \mathrm{min})$. The detector was operated in full scan mode $(\mathrm{m} / \mathrm{z}$ 50-650) and electron ionisation (EI) mode. For additional analytical information on the fractions, analyses were performed with negative chemical ionisation (NCI) operated in full scan mode $(\mathrm{m} / \mathrm{z} 50-650)$ and Selected Ion Monitoring (SIM) for chlorine $(\mathrm{m} / \mathrm{z} 35 / 37)$ and bromine content $(m / z 79 / 81)$ with the same column and column temperature programme as described above.

Mass spectra were deconvoluted using the Automated Mass Spectral Deconvolution and Identification System (AMDIS version 2.64) and compared with reference spectra in the National Institute of Standards and Technology (NIST version 02) main mass spectral database (match factor $\geq 80 \%$ ) for tentative identification. The Kovats Retention Indices (KRI) values were used to identify the compounds using the Quality Peak Identification Database (QPID) that was partly developed in the framework of the MODELKEY project. This database stores unknowns after attributing them a number, which are recognised peaks according to a number of established GC/MS settings, e.g. peak shape, purity of spectra, intensity check etc. These unknowns will later be thoroughly evaluated within the MODELKEY project and comparisons on the emergence of specific pollutants can be made between sample locations. It is also possible to separate interesting compounds from the trivial ones by using filters present in the QPID software. In our study, the background contamination (i.e. compounds present in analytical blank samples) as well as compounds present in adjacent, non-active fractions was subtracted from the active fraction result list. Only the interesting compounds (i.e. present only in the active fractions) and the number of unknowns are reported here.

\section{Results}

\section{Anti-androgenicity}

The AR antagonistic activity originally observed in the toxicity screening of the river sediments performed within MODELKEY was confirmed in the total extract, i.e. GPC1 (200 nmol FLU eq/g dw, Table 1). The AR antagonistic potency following reversed phase fractionation was $110 \mathrm{nmol} \mathrm{FLU} \mathrm{eq/g} \mathrm{dw} \mathrm{in} \mathrm{fraction} 3$ (RP3) and $25 \mathrm{nmol}$ FLU eq/g dw in fraction 4 (RP4; Fig. 4a). Summation of activity shows that the potency was $30 \%$ lower than in the original extract GPC1. Following normal phase subfractionation, two groups of potent $\mathrm{AR}$ antagonistic fractions were distinguished, i.e. normal phase sub-fractions 2 of reversed-phase fractions 3 and 4 (RP3NP2 + RP4NP2) and normal phase sub-fractions 5 and 6 of reversed-phase fractions 3 (RP3NP5 + RP3NP6; Fig. 4a). A total AR antagonistic activity of $59 \mathrm{nmol} \mathrm{FLU}$ eq/g dw was found by summation of all normal phase sub-fractions together, i.e. about $50 \%$ lower than in the original reversed-phase fractions (Fig. 5a). When all normal phase sub-fractions (NP1-8) of reversed-phase fraction RP3 were pooled into the original reversed-phase constitution and re-tested in the

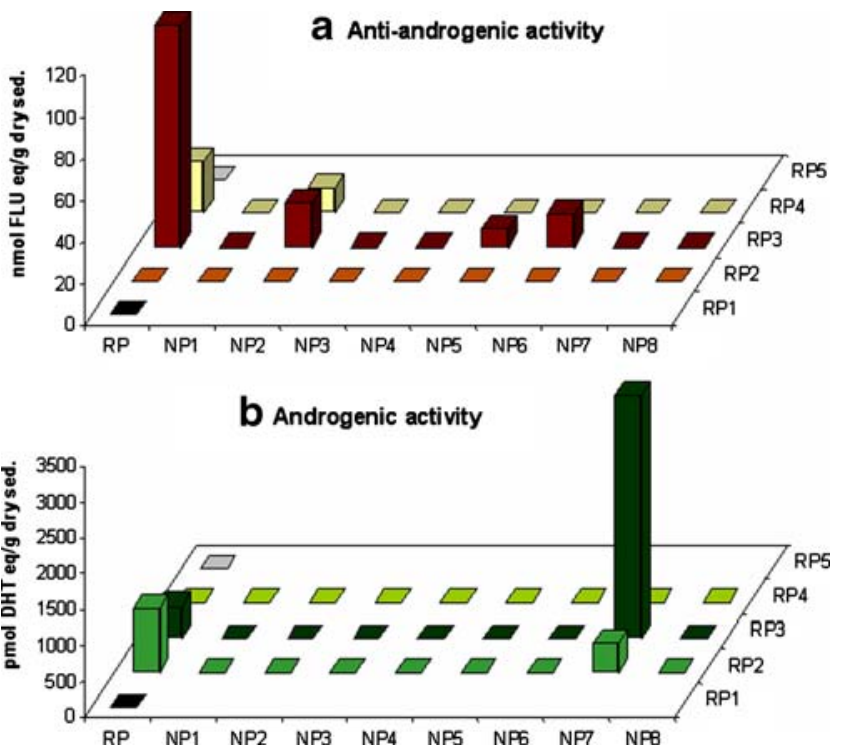

Fig. 4 Anti-androgenic (a) and androgenic (b) responses in $A R$ CALUX (nmol FLU eq/g dw and pmol DHT eq/g dw, respectively) in reversed-phase fractions (RP1-5) and normal phase sub-fractions (NP1-8) 


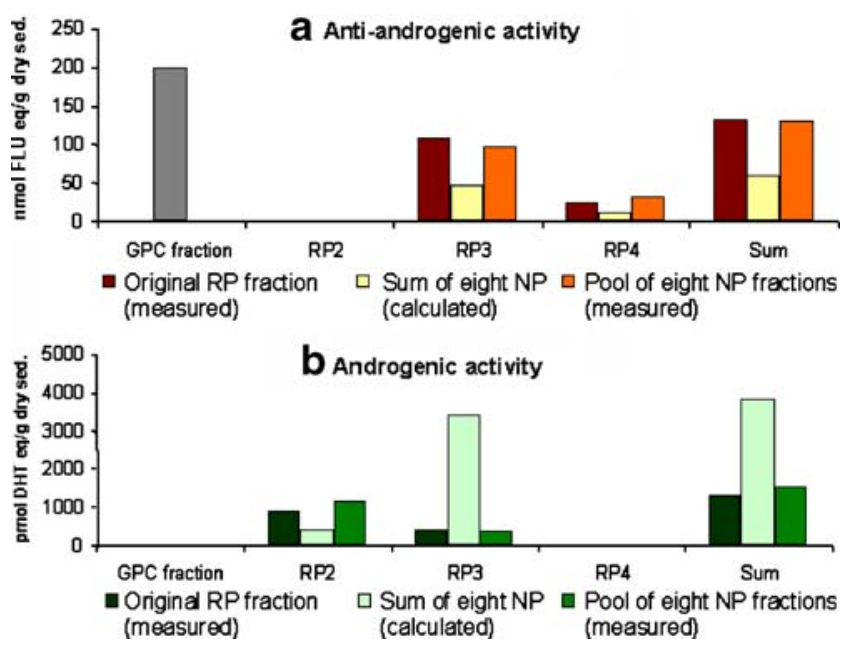

Fig. 5 A comparison of bioassay results obtained in GPC fraction, individual reversed-phase fractions (RP) and normal phase (NP) subfractions compared to pooled NP fractions to illustrate the AR antagonistic (a) and AR agonistic (b) potency recovery and interactions

bioassay, the original AR antagonistic potency was obtained again, i.e. $98 \mathrm{nmol} \mathrm{FLU} \mathrm{eq/g} \mathrm{dw} \mathrm{(Fig.} \mathrm{5a).} \mathrm{The}$ same was observed following pooling of the normal phase sub-fractions of reversed-phase fraction RP4 (34 nmol FLU eq/g dw). The decrease in total AR antagonistic potency after sub-fractionation was recovered, indicating either a synergistic effect of all present compounds, or that the bioassay is not sensitive enough to detect all AR antagonistic effects present in the separate normal phase subfractions.

\section{Androgenicity}

Upon screening in the AR CALUX assay, no detectable agonistic androgenic activity was present in the total sediment sample extract, i.e. GPC1 (Table 1). After the first fractionation on the reversed-phase column, however, a significant AR agonistic activity was measured in reversedphase fractions 2 (RP2) and 3 (RP3), 890 and 440 pmol DHT eq/g dw, respectively (Fig. 4b). Thus, reversed-phase fraction 3 possesses an AR antagonistic as well as AR agonistic potency. The observed AR agonistic potency of RP2 was lower after normal phase sub-fractionation, and the remaining activity was found in normal phase fraction 7 (RP2NP7, $420 \mathrm{pmol}$ DHT eq/g dw). In normal phase subfraction 7 of reversed-phase fraction 3 (RP3NP7), an AR agonistic potency of $3,400 \mathrm{pmol}$ DHT eq/g dw was observed, which is almost eight times higher than in the original fraction RP3 (Fig. 4b).

Following pooling of all normal phase sub-fractions of reversed-phase fraction 3 into the original RP3 constitution and re-tested in the bioassay, the original AR agonistic potency of RP3 was interestingly obtained again (380 pmol DHT eq/g dw) (Fig. 5b), suggesting that antagonistic compounds present in the other normal phase subfractions than the active RP3NP7 masked the agonistic potency in RP3. The opposite effect was observed when RP2 normal phase sub-fractions were pooled and re-tested, the AR agonistic activity was increased to its original RP2 potency, showing that the lower potency found following normal phase fractionation was not due to loss of compounds. This might be due to either synergism between compounds present in the RP2 fraction or low sensitivity of the bioassay when analysing the normal phase sub-fractions of RP2.

\section{Chemical screening}

In the normal phase sub-fractions active in the AR CALUX bioassay, chemical screening revealed the tentative identity of seventeen compounds (Table 2) with the GC/MS settings applied in the AMDIS deconvolution procedure, and as many as 71 unknown spectra were added to the QPID database for further investigation (Table 3).

The two distinguished groups of sub-fractions with AR antagonistic activity contained structurally different compounds. The first group of fractions (RP3NP2 + RP4NP2), eluting early on the normal phase column, contains nonpolar compounds. Many polycyclic aromatic hydrocarbons (PAHs) were detected in RP3NP2 (Fig. 6a, Table 2) and RP4NP2 (chromatogram not shown), together with 28 unknown peaks, i.e. peaks that fulfil the GC/MS setting criteria and not present in non-active fractions or procedural blank fractions (attributed peak-numbers in Table 3). Moderately polar compounds are expected to be present in the second group (RP3NP5 + RP3NP6). Apart from a technical nonylphenol mixture, 4'-Propoxy-2-methylpropiophenone, 4-tert-pentylphenol, $N$-[4-(phenylamino)phenyl]benzamide, and dibutylphthalate (Table 2), 41 unknown peaks (Table 3) were detected in the fractions RP3NP5 (Fig. 6b) and RP3NP6 (chromatogram not shown).

Tris(1-chloro-2-propyl) phosphate was the only tentatively identified compound in the AR agonistic potent fraction RP2NP7 (Table 2). Two distinct isomer clusters, with GC-retention between 18-26 $\mathrm{min}$ and 40-52 $\mathrm{min}$, were detected in EI mode in both fractions RP2NP7 (Fig. 6c) and RP3NP7, but in the latter fraction, the cluster was more intense (chromatogram not shown). The first cluster was not detected in NCI mode but the second was. The clusters did not contain any bromines or chlorines and are yet of unknown identity. The AR agonistic potent fractions contained only two unknown peaks (Table 3). The low number of peaks may be an indication that GC/MS is not the preferred method for analysis of the more polar compounds, such as natural hormones. 


\section{Discussion}

Effect-directed analysis

This study shows that the application of EDA to a contaminated sediment sample unravels the different contributions to the observed biological activity, in our case in the AR CALUX assay, and leads to a distinction of both agonistic and antagonistic effects. This is an important step towards the identification of potential endocrine disrupting compounds that can interfere with the androgen hormone system. The compounds identified here have been distinguished purely based on their activity in the bioassay and not due to their presence on priority lists, production volumes or prediction models, as is commonly the case. EDA studies have earlier revealed that a majority of key toxicants present in European water systems could not be found on the list of priority pollutants [9]. EDA is therefore a powerful tool to discover a wide range of biologically active contaminants, including emerging pollutants as well as 'classical' toxicants. The early detection of the presence of key toxicants that may hamper the chemical and/or ecological status enables the implementation of monitoring campaigns for environmental pollutants that are not, or not yet, routinely monitored.

In the sample investigated in this study, the AR agonistic potency is clearly concealed by the effects of AR antagonists in the total extract (GPC1), demonstrating that toxicity screening of total extracts is not enough to evaluate the full in vitro endocrine disrupting potential of a complex chemical mixture as found in the environment. The two-step serial fractionations enable the separation of androgenic and anti-
Table 2 Tentatively identified compounds (match factor $\geq 80 \%$ in NIST database) found in fractions with a specified activity (androgen receptor agonistic or antagonistic), with the compound name, CAS number, Logarithm octanol-water coefficient $\left(\log K_{\text {ow }}\right)^{\text {a }}$, the structure of each compound and the androgenic activity according to literature

\begin{tabular}{|c|c|c|c|c|c|c|}
\hline Fraction & AR activity & Name & CAS number & Log $K_{\text {ow }}$ & Structure & Literature \\
\hline RP2NP7 & Agonistic & Tris (1-chloro-2-propoyl) phosphate & $13674-84-5$ & 2.89 & & $\begin{array}{c}\text { Anti- } \\
\text { androgenic } \\
{[38-41]}\end{array}$ \\
\hline RP3NP2 & Antagonistic & Fluoranthene & $206-44-0$ & 4.93 & & $\begin{array}{c}\text { Anti- } \\
\text { androgenic } \\
{[27]}\end{array}$ \\
\hline $\begin{array}{l}\text { RP3NP2 and } \\
\text { RP4NP2 }\end{array}$ & Antagonistic & Benz[a]anthracene & $56-55-3$ & 5.52 & & $\begin{array}{c}\text { Anti- } \\
\text { androgenic } \\
{[27]}\end{array}$ \\
\hline RP3NP2 & Antagonistic & Pyrene & $129-00-0$ & 4.93 & & $\begin{array}{c}\text { Not active } \\
\text { [27] }\end{array}$ \\
\hline RP3NP2 & Antagonistic & Phenanthrene & $85-01-8$ & 4.35 & & $\begin{array}{c}\text { Not active } \\
\text { [27] }\end{array}$ \\
\hline RP3NP2 & Antagonistic & 1,3-bis(1,1-Dimethylethyl)-benzene & $1014-60-4$ & 5.81 & & $\begin{array}{l}\text { No data } \\
\text { available }\end{array}$ \\
\hline RP3NP2 & Antagonistic & o-Terphenyl & $84-15-1$ & 5.52 & & $\begin{array}{l}\text { No data } \\
\text { available }\end{array}$ \\
\hline RP3NP2 & Antagonistic & $p$-Terphenyl & $92-94-4$ & 5.52 & & $\begin{array}{l}\text { No data } \\
\text { available }\end{array}$ \\
\hline RP3NP2 & Antagonistic & 4-Methyl-phenanthrene & 832-64-4 & 4.89 & & $\begin{array}{l}\text { No data } \\
\text { available }\end{array}$ \\
\hline RP3NP2 & Antagonistic & 1,4-bis(Phenylmethyl) benzene & 793-23-7 & 6.04 & & $\begin{array}{l}\text { No data } \\
\text { available }\end{array}$ \\
\hline
\end{tabular}




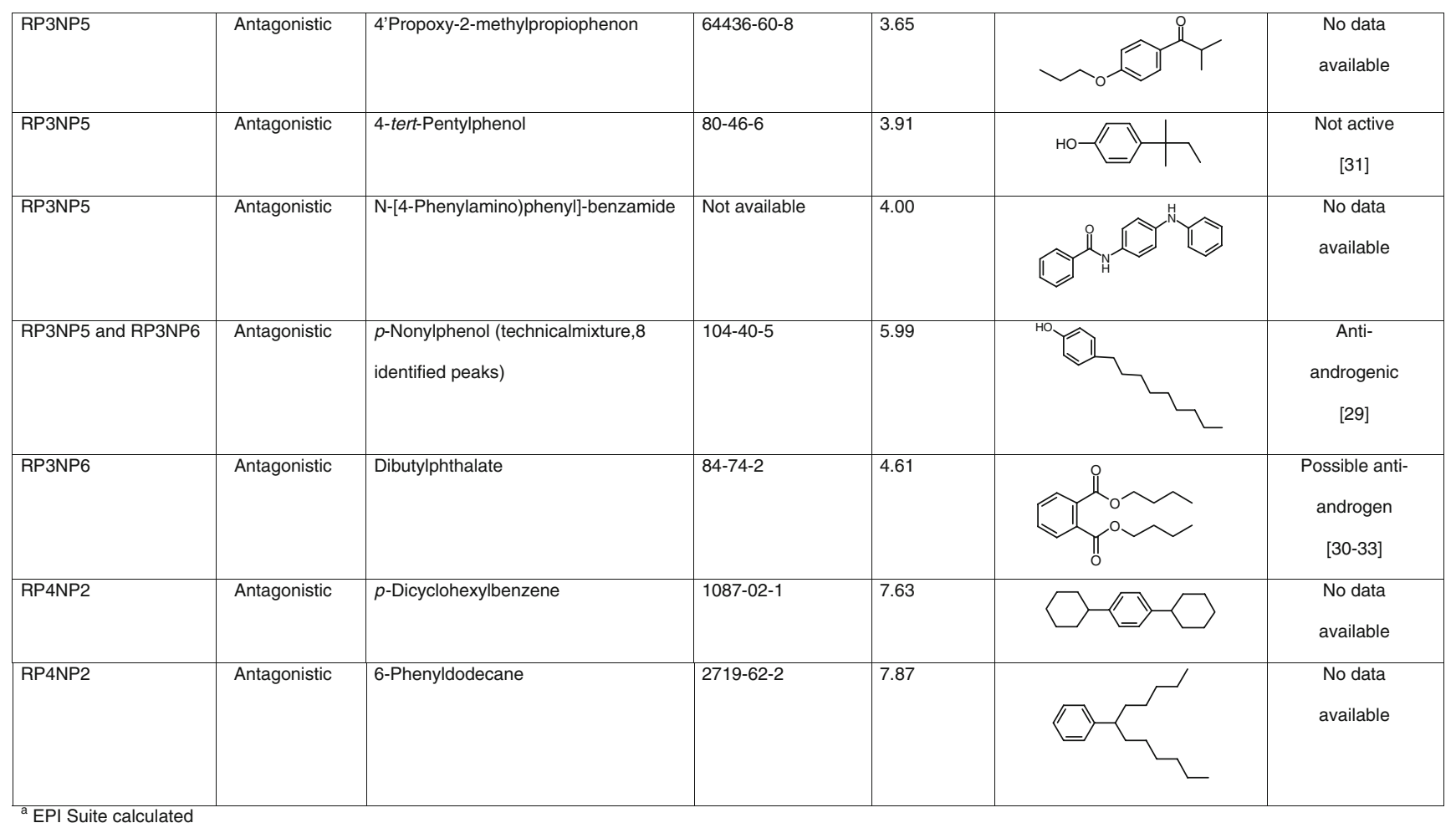

androgenic compounds into different sub-fractions. The masking of the AR agonistic effect by antagonistic compounds has been reported earlier; e.g. in sediment sample from the river Lambro, Italy and in paper and pulp mill effluents. In both cases, antagonistic but no agonistic AR activity was observed in the total extracts, but AR agonistic activity appeared following reversed phase fractionation $[13,23]$. In the latter report, it was suggested that the AR agonistic activity could be attributed to natural compounds originated from decaying wood [23].

Anti-androgenic activity

The anti-androgenic activity observed in the total extract (GPC1) was detected in reversed-phase fractions RP3 and RP4 (Table 1). From the reversed phase fractionation procedure, it can be derived that the log octanol/water coefficient $\left(\log K_{\text {ow }}\right)$ of the AR antagonists present in RP3 and RP4 will be between 4-6 and 6-9 $( \pm 0.5$ according to Schymanski et al. [24]), respectively, based on a tested chemical mixture containing compounds with a wide range of $\log K_{\mathrm{ow}} \mathrm{s}$ [19]. Normal phase sub-fractionation successfully separated two potent chemical groups from each other, decreasing the complexity of the matrix and simplifying the identification of compounds by chemical analysis. The first anti-androgenic compound group consisted of lipophilic aromatic compounds, such as PAHs (Table 2). PAHs are a class of organic aromatic compounds comprising several congeners that are ubiquitous in the environment and in foodstuffs. They originate from the incomplete combustion of fossil fuels, oil spills and industrial processes. PAHs are reported at high concentrations in the marine environment

Table 3 The number of unknowns $(n)$ in each androgenic and anti-androgenic active sub-fraction and the attributed number (\#) given in the QPID database

\begin{tabular}{llcl}
\hline Fraction & Activity & Unknowns (n) & Unknown (\#) \\
\hline RP2NP7 & Androgenic & 1 & 61 \\
RP3NP7 & Androgenic & 1 & 2 \\
RP3NP2 & Anti-androgenic & 22 & $65,72,74,81,85,87,95,98,107,112-114,117,119-127$ \\
RP4NP2 & Anti-androgenic & 6 & $42,50,54,63,76,84$ \\
RP3NP5 & Anti-androgenic & 33 & $1,3-34$ \\
RP3NP6 & Anti-androgenic & 8 & $5,14,29,34,77,97,116,118$ \\
Total & & 71 & \\
\hline
\end{tabular}


Fig. 6 Total ion chromatogram (TIC) GC/MS chromatogram with electron ionisation (EI) of the anti-androgenic potent fraction RP3NP2 (a), the antiandrogenic potent fraction RP3NP5 (b) and the androgenic potent fraction RP2NP7 (c)
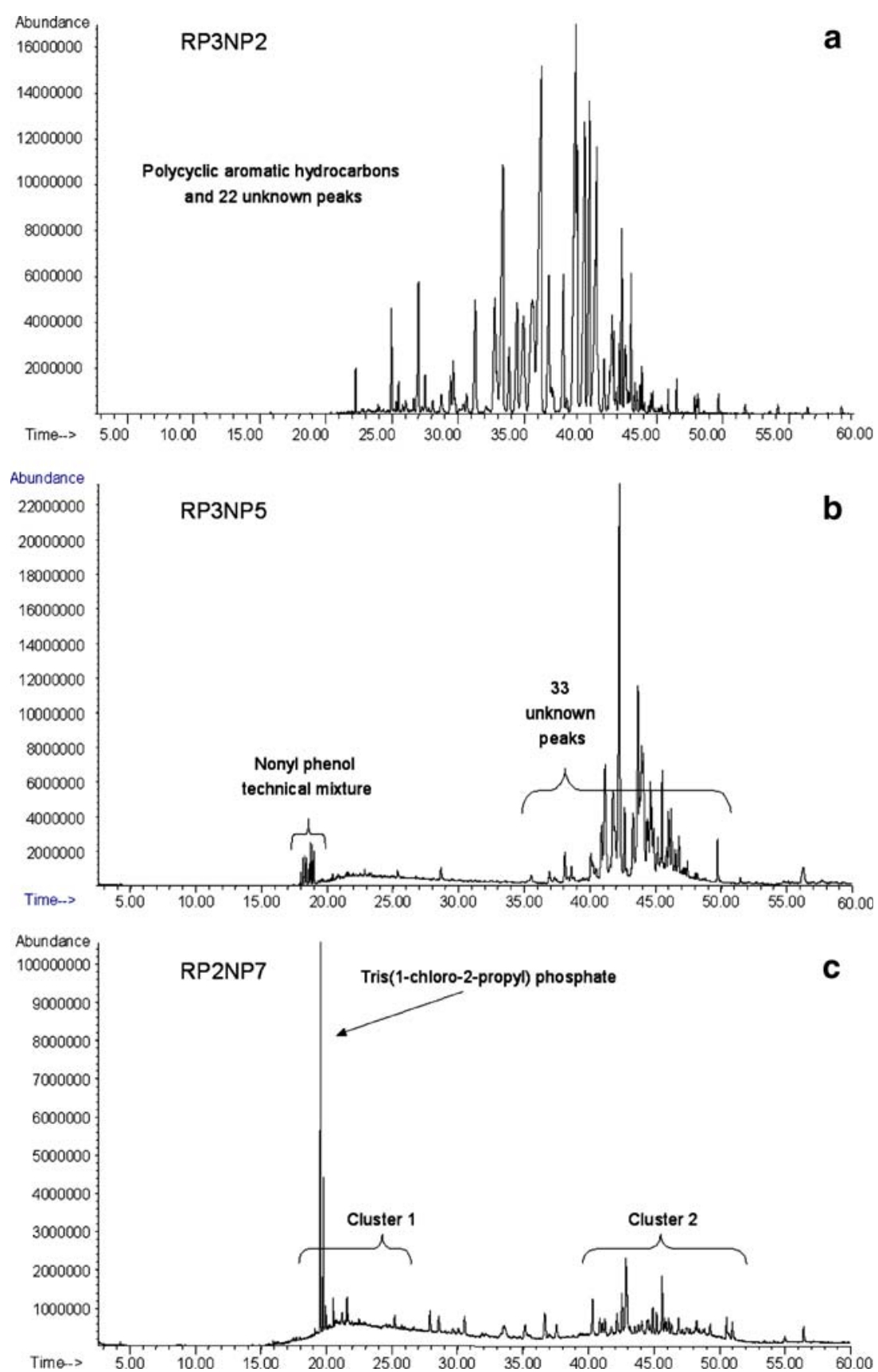

( $\Sigma 16$ PAHs), e.g. up to $52 \mu \mathrm{g} / \mathrm{g}$ sed. in the Gulf of Gdansk of the Baltic Sea [25] and $10 \mu \mathrm{g} / \mathrm{g}$ sed. in Lake Pilnok in the Czech Republic [26]. Target analysis of PAHs in the sediment sample investigated in this study resulted in $5 \mu \mathrm{g} / \mathrm{g} \mathrm{dw}$ (not yet published). Some PAHs tentatively identified in RP3NP2 and RP4NP2 are able to act as antiandrogens (e.g. benzo[a]anthracene, and fluoranthene), whereas others (e.g. pyrene and phenanthrene) are not able to inhibit androgen receptor transactivation [27]. Fluoranthene was the most dominant PAH congener in the target analysis, followed by pyrene. In petroleum-derived PAHs, pyrene is more abundant than fluoranthene, but at higher combustion temperatures a predominance of fluoranthene over pyrene is characteristic. As such, a ratio value (flu/ pyr) greater than 1 is classically related to pyrogenic sources, e.g. coal burning, wood burning, vehicular exhaust emission, waste crankcase oil and asphalt roofing material [28].

In the second, more polar group of anti-androgenic subfractions (RP3NP5 + RP3NP6), a technical mixture of nonylphenol could be tentatively identified (Table 2). Nonylphenol has been identified in estuaries in the UK [12], and has been reported to act as a potent AR antagonist in a yeast-based bioassay [29]. 
The observations regarding anti-androgenic activity of dibutylphthalate (DBP), tentatively identified in RP3NP6, is not consistent in literature. Phthalates, such as DBP, have been demonstrated to be an environmental anti-androgen in vivo that disrupts androgen-regulated rat male sexual differentiation via a non-receptor mediated mechanism [30]. Although, DBP has been reported to be unable to exhibit an anti-androgenic potency in a cell-based ( $\mathrm{CHO}$ $\mathrm{K} 1$ cells) in vitro bioassay at a maximum concentration of $10 \mu \mathrm{M}$ [31], another study with the same cell line reported anti-androgenic potency at $4.8 \mu \mathrm{M}$ [32]. Additionally, an in vitro receptor binding assay reported weak binding to the androgen receptor with an $\mathrm{IC}_{50}$ of $27.5 \mu \mathrm{M}$ [33]. It can be concluded that phthalates exhibit anti-androgenic activity but with which mechanism and to which extent is still unclear.

No information was available regarding the (anti-) androgenic potency of the other tentatively identified compounds.

\section{Androgenic activity}

The AR agonistic potency masked by AR antagonists in the total extract (GPC1) was successfully revealed by the twostep serial fractionations. The identification of active fractions simplifies the chemical analytical identification of potent AR agonistic compounds. The predicted $\log K_{\text {ow }} \mathrm{S}$ of the AR agonists present in RP2 and RP3 will be between 2-4 and 4-6, respectively. It can also be expected that compounds eluting late in the normal phase subfractionation are rather polar. Despite the well reported potencies of steroid androgens, i.e. the natural hormone testosterone and its natural and synthetic derivatives [11, 34], there are no data available on exogenous pollutants being potent in vitro androgen receptor agonists. Out of 202 natural, synthetic and environmental chemicals evaluated in an extensive in vitro androgen receptor binding study, only 14 of the tested compounds exhibited strong binding to the AR, all of which were steroids [33]. The $\log K_{\mathrm{ow}} \mathrm{s}$ of these steroids fit the expected $\log K_{\text {ow }}$ of the AR agonistic potent fractions ( $\left.\log K_{\text {ow }} 2-6\right)$.

A large amount of anabolic steroid hormones are synthesised and sold to be potent androgens in human and animal treatments [5-8]. The estimated yearly excretion of androgens by farm animals was 7 tons in the European Union in the year 2000 [35]. The environmental fate of steroids originating from livestock excreta seems to be strongly influenced by storage conditions and also by the soil type of the fields where the dung is spread [35]. Synthetic and natural androgens from human activity have been reported to be stable enough to be present in the effluent of waste water treatment plants although the majority of them are successfully removed [11, 36, 37].
DHT, androstenedione, androstanedione, $5 \beta$-androstane$3 \alpha, 11 \beta$-diol-17-one, androsterone and epi-androsterone were identified in sewage treatment works effluents in the UK and held responsible for $99 \%$ of the in vitro androgenic activity determined [11]. In the present study, the only tentatively identified compound in the androgenic fraction was an organophosphate used as flame retardant (Table 2), but organophosphates have been reported to be strong androgenic antagonists [38-41]. More interesting are the two unidentified clusters of non-halogen (chlorine or bromine) compounds (Fig. 6c). The intensity of the clusters increases from RP2NP7 to RP3NP7, corresponding with the higher androgenic potency of the latter fraction (Table 1), assuming that the ionisation efficiency of the individual compounds is the same.

According to the fractionation scheme published by Houtman et al. [15], estrogens are expected to elute in reversed-phase fraction 2. Many of the known-to-be-present estrogens can act as AR antagonists [42], although in this study, no anti-androgenic activity was detected in RP2, only agonistic androgenicity. Androgens and estrogens are similar in structure and expected to have comparable log $K_{\mathrm{ow}}$, and hence elute in the same fractions. It may therefore be possible that estrogens present in the AR agonistic fraction RP2NP7 still mask its full in vitro androgenic potency. GC/MS techniques are not optimal for the analysis of estrogens and androgens due to their high polarity, although it is possible after derivatisation of the fractions, and a careful choice of analytical GC column [17].

Interactions between AR agonists and antagonists

The AR antagonistic potency was lower after fractionation, from GPC1 (200 nmol FLU/g dw, to RP3 and RP4 (130 nmol FLU/g dw together) and finally following normal phase fractionation in RP3NP2, RP3NP5, RP3NP6 and RP4NP2 (59 nmol FLU/g dw together; Fig. 5a). Due to the additional confirmation step where the normal phase fractions were pooled and re-tested in the bioassay (130 nmol FLU/g dw) it can be concluded that the analytical recovery of the active compounds following the two-step serial fractionations is at least $65 \%$ (from total activity $200 \mathrm{nmol} \mathrm{FLU/g} \mathrm{dw} \mathrm{to} 130 \mathrm{nmol} \mathrm{FLU/g} \mathrm{dw).} \mathrm{Also}$ the agonistic androgenic activity in reversed-phase fraction $(1,330 \mathrm{pmol} \mathrm{DHT} / \mathrm{g} \mathrm{dw})$ was recovered by pooling the normal phase sub-fractions (1,550 pmol DHT/g dw), illustrating that no compounds were lost during normal phase sub-fractionation (Fig. 5b). Unfortunately, it was not possible to pool all reversed-phase fractions into their original total extract constitution (GPC1) and to re-test it in the bioassay, due to the lack of any remaining extract.

Reversed-phase fraction RP3 was able to both induce and inhibit the AR activity. The observed effect could be explained 
by the knowledge of the so-called partial agonists. These compounds (e.g. alkylphenols) have an anti-androgenic effect despite the fact that they can bind and activate the AR. The partial AR agonists, however, cause a much lower maximum response than true AR agonistic compounds, even when all receptors are occupied. In the presence of true agonists, partial agonists therefore inhibit the effect of the true agonists and thus act as anti-androgens [21, 43]. The separation of partial AR agonists present in fraction RP3NP7 from AR antagonistic fractions (RP3NP2, RP3NP5, RP3NP6) can be the explanation of the lower total AR antagonistic potency of the normal phase sub-fractions $\left(\Sigma_{\mathrm{RP} 3 \mathrm{NP} 1-8} 47 \mathrm{nmol} \mathrm{FLU} / \mathrm{g} \mathrm{dw}\right.$, Table 1) compared to the original AR antagonistic potency of the reversed-phase fraction RP3 (110 nmol FLU/g dw, Fig. 5a and b).

\section{Concluding remarks}

Through the use of EDA fractionation strategies, it was demonstrated that androgenic and anti-androgenic compounds present in a sediment sample influence each other's interaction with the androgen receptor. The AR agonistic effect appeared following both reversed and normal phase sub-fractionation, but the potency was masked again after pooling the normal phase sub-fractions.

As literature has indicated, it is likely that the PAHs, nonylphenol and possibly DBP are contributing to the antiandrogenic potency observed in the river sediment sample analysed in this study. With the GC/MS screening method applied here, no compounds with AR agonistic disrupting potencies could be (tentatively) identified, suggesting that LC/ MS may be a better choice for identification of the compounds responsible for the observed $\mathrm{AR}$ agonistic activity.

The power of EDA lies in its suitability to reveal the emergence of novel environmental pollutants, including the unravelling of agonistic and antagonistic effects in the same sample, but there are several aspects inherent to the strategy that need to be addressed.

Generally, in EDA studies, no internal standards or reference compounds are added to the sample because of the possibility that these may disturb the bioassay results. Hence, it is not possible to accurately calculate concentrations of tentatively identified compounds in the active fractions. Instead, it is advisable to carry out target analysis of the identified compounds in remaining sample(s) from the same locations.

In EDA studies, exhaustive extraction is usually applied to the sediment samples in order to obtain information on all the compounds present, ignoring the fact that under normal conditions certain compounds may be more bioavailable than others. In the case of the presence of both agonistic and antagonistic compounds (in a given assay), the assessment of the biological availability of the identified compounds in the original sample is an important aspect.

There is a need to fully investigate the environmental behaviour (bioavailability, persistency, distribution, metabolism, etc.) of the identified potent compounds, so that the assessment of the environmental risk is firmly based on relevant data. As a first step, the environmental behaviour of the identified compounds can to some extent be derived from the fractionation schemes, where the distribution/ elution of compounds depends on the physico-chemical properties, e.g. molecular weight, lipophilicity and polarity.

Future efforts will be put into identification of the unknown active compounds $(n=71$, Table 3$)$ in these fractions. Other sophisticated analytical techniques (e.g. accurate mass LC/MS) will be used to target complementary groups of compounds, i.e. less volatile and more polar compounds such as the natural hormones and pharmaceuticals. A summary of all toxicological and chemical analyses on the river samples will be published within the project MODELKEY (www.modelkey.org).

Acknowledgement We thank Bert van Hattum (IVM, VU University, The Netherlands), Eric de Deckere (University of Antwerp, Belgium), Sander van Vliet (National Institute for Coastal and Marine Management, The Netherlands) and Chris van Liefferinge (University of Antwerp, Belgium) for collecting the samples, Peter Cenijn (IVM, VU University, The Netherlands) for technical assistance and Jan Balaam (CEFAS, United Kingdom) for additional analyses. This work was done in the framework of the EU-supported programme MODELKEY (Contract-No. 511237 (GOCE)) and the Marie Curie Research Training Network KEYBIOEFFECTS (MRTN-CT-2006-035695).

Open Access This article is distributed under the terms of the Creative Commons Attribution Noncommercial License which permits any noncommercial use, distribution, and reproduction in any medium, provided the original author(s) and source are credited.

\section{References}

1. Hotchkiss AK, Rider CV, Blystone CR, Wilson VS, Hartig PC, Ankley GT, Foster PM, Gray CL, Gray LE (2008) Toxicol. Sci $105: 235-259$

2. WHO (2002) Global assessment of the state-of-the-science of endocrine disruptors. International Programme on Chemical Safety, Geneva, Switzerland

3. Mills LJ, Chichester C (2005) Sci Total Environ 343:1-34

4. Ankley G, Mihaich E, Stahl R, Tillit D, Colborn T, McMaster S, Miller R, Bantle J, Cambell P, Denslow N, Dickerson R, Folmar L, Fry M, Giesy J, Gray LE, Guiney P, Hutchinson T, Kennedy S, Kramer V, LeBlanc G, Mayes M, Nimrod A, Patino R, Peterson R, Purdy R, Ringer R, Thomas P, Touart L, van der Kraak G, Zacharewski T (1998) Environ Toxicol Chem 17:68-87

5. Yu NH, Ho ENM, Leung DKK, Wan TSM (2005) J. Pharm. Biomed. Anal 37:1031-1038

6. Wood RI (2008) Front. Neuroendocrinol 29:490-506

7. Meyer HHD (2001) Acta Pathol. Microbiol. Immunol. Scand 109:1-8

8. Gooren LJG, Bunck MCM (2004) Drugs 64:1861-1891

9. Brack W (2003) Anal Bioanal Chem 377:397-407 
10. Grung M, Lichtenthaler R, Ahel M, Tollefsen K-E, Langford K, Thomas KV (2007) Chemosphere 67:108-120

11. Thomas KV, Hurst MR, Matthiessen P, McHugh M, Smith A, Waldock MJ (2002) Environ Toxicol Chem 21:1456-1461

12. Thomas KV, Thain JE, Waldock MJ (1999) Environ Sci Technol 18:401-411

13. Urbatzka R, Van Cauwenberge A, Maggioni S, Viganò L, Mandich A, Benfanati E, Lutz I, Kloas W (2007) Chemosphere 67:1080-1087

14. Houtman CJ, Cenijn PH, Hamers T, Lamoree MH, Legler J, Murk AJ, Brouwer A (2004) Environ Toxicol Chem 23:32-40

15. Houtman CJ, Booij P, Jover E, del Rio Pascual D, Swart K, van Velzen M, Vreuls R, Legler J, Brouwer A, Lamoree MH (2006) Chemosphere 65:2244-2252

16. Grote M, Brack W, Altenburger R (2005) Environ Toxicol 20:475-486

17. Houtman CJ, van Oostveen AM, Brouwer A, Lamoree MH, Legler J (2004) Environ Sci Technol 38:6415-6423

18. Seiler T-B, Schulze T, Hollert H (2008) Anal Bioanal Chem 390:1975-1985

19. Houtman CJ. Tracing endocrine disruptors - identification and effects of endocrine disrupting compounds in the aquatic environment. Thesis. 2007. Institute for Environmental Studies (IVM), VU University, Amsterdam, The Netherlands.

20. Fernandez P, Bayona JM (1992) J Chromatogr 625:141-149

21. Sonneveld E, Jansen HJ, Riteco JAC, Brouwer A, Van der Burg B (2005) Toxicol Sci 83:136-148

22. Brack W, Schmitt-Jansen M, Machala M, Brix R, Barceló D, Schymanski E, Streck G, Schulze T (2008) Anal Bioanal Chem 390:1959-1973

23. Svenson A, Allard A-S (2004) Environ Toxicol 19:510-517

24. Schymanski EL, Meinert C, Meringer M, Brack W ((2008) Anal Chim Acta 615:136-147

25. Falandysz J, Albanis T, Bachmann J, Bettinetti R, Bochentin I, Boti V, Bristeau S, Daehne B, Dagnac T, Galassi S, Jeannot R, Oehlmann J, Orlikowska A, Sakkas V, Szczerski R, Valsamaki V,
Schulte-Oehlmann U (2006) J Environ Sci Health Part A 41:2127-2162

26. Mazurová E, Hilscherová K, Jálová V, Köhler HR, Triebskorn R, Giesy JP, Bláha L (2008) Aquat Toxicol 89:172-179

27. Vinggaard AM, Hnida C, Larsen JC (2000) Toxicol 145:173-183

28. Sanders M, Sivertsen S, Scott G (2002) Arch Environ Contam Toxicol 43:438-448

29. Lee HJ, Chattopadhyay S, Gong E-Y, Ahn RS, Lee K (2003) Toxicol Sci 75:40-46

30. Mylchreest E, Sar M, Cattley RC, Foster PMD (1999) Toxicol Appl Pharmacol 156:81-95

31. Roy P, Salminen H, Koskimies P, Simola J, Smeds A, Saukko P, Huhtaniemi IT (2004) J Steroid Biochem Mol Biol 88:157-166

32. Takeuchi S, Iida M, Kobayashi S, Jin K, Matsuda T, Kojima H (2005) Toxicol 210:223-233

33. Fang H, Tong W, Branham WS, Moland CL, Dial SL, Hong H, Xie Q, Perkins R, Owens W, Sheehan DM (2003) Chem Res Toxicol 16:1338-1358

34. Sonneveld E, Riteco JAC, Jansen HJ, Pieterse B, Brouwer A, Schoonen WG, Van der Burg B (2006) Toxicol Sci 89:173-187

35. Lange IG, Daxenberger A, Schiffer B, Witters H, Ibaretta D, Meyer HHD (2002) Anal Chim Acta 473:27-37

36. Kolodziej EP, Gray JL, Sedlak DL (2003) Environ Toxicol Chem $22: 2622-2629$

37. Kirk LA, Tyler CR, Lye CM, Sumpter JP (2002) Environ Toxicol Chem 21:972-979

38. Andersen HR, Vinggaard AM, Rasmussen TH, Gjermandsen IM, Bonefeld-Jørgensen EC (2002) Toxicol Appl Pharmacol 179:1-12

39. Kitamura S, Suzuki T, Ohta S, Fujimoto N (2003) Environ Health Perspect 111:503-508

40. Tamura H, Maness SC, Reischmann K, Dorman DC, Gray E, Gaido KW (2001) Toxicol Sci 60:56-62

41. Xu L-C, Liu L, Ren X-M, Zhang M-R, Cong N, Xu A-Q, Shao JH (2008) Toxicol 243:59-65

42. Sohoni P, Sumpter JP (1998) J Endocrin 158:327-339

43. Singh SM, Gauthier S, Labrie F (2000) Curr Med Chem 7:211-247 